\title{
Postmortem histopathological examination of changes due to systemic ischemia/hypoxiain the thyroid gland
}

\author{
Tomoya Ikeda ${ }^{1,2}$, Naoto Tani ${ }^{1,2}$, Tomomi Michiue ${ }^{1,2}$, Shigeki Oritani ${ }^{1}$, Fumiya Morioka ${ }^{1}$, Stefan Potente ${ }^{1,3}$ and Takaki Ishikawa $^{1,2}$ \\ ${ }^{1}$ Department of Legal Medicine, Osaka City University Medical School, Asahi-machi 1-4-3, Abeno, Osaka 545-8585, Japan \\ ${ }^{2}$ Forensic Autopsy Section, Medico-legal Consultation and Postmortem Investigation Support Center, c/o Department of Legal Medicine, Osaka City University \\ Medical School, Asahi-machi 1-4-3, Abeno, Osaka 545-8585, Japan \\ ${ }^{3}$ Institute of Forensic Medicine, University Hospital, Goethe-University, Kennedyallee 104, Frankfurt/Main 60596, Germany
}

\begin{abstract}
We investigated histopathological analysis of changes caused by systemic ischemia/hypoxia in the thyroid gland owing to acute mechanical asphyxia by neck compression or blunt head injury and compared the changes with those due to other types of deaths, including drowning and sudden cardiac death. A total of 96 forensic autopsies cases ( 64 males and 32 females) performed at our institute were examined; the age range and postmortem interval of these cases were $25-96$ years (median, 67 years) and 12-72 h (median, $24 \mathrm{~h}$ ), respectively. Cause of death in these cases were asphyxia $(\mathrm{n}=21 ; \mathrm{hanging}, \mathrm{n}=8$; strangulation, $\mathrm{n}=6$; and others, $\mathrm{n}=7$ ), blunt injury ( $\mathrm{n}=17$; acute/subacute head injury, $\mathrm{n}=11$; acute/subacute non-head injury, $\mathrm{n}=6)$, sharp instrument injury $(\mathrm{n}=6)$, drowning $(\mathrm{n}=9$; excluding drowning in the bathtub), fire fatalities [ $\mathrm{n}=37$; carbon monoxide hemoglobin $(\mathrm{CO}-\mathrm{Hb})$ level $<30 \%, \mathrm{n}=10 ; \mathrm{CO}-\mathrm{Hb}$ level = 30-60\%, $\mathrm{n}=16$; CO-Hblevel > 60\%, $\mathrm{n}=11$ ], and acute myocardial infarction/ischemia $(n=6)$, without medical intervention. Serial horizontal sections of formalin-fixed, paraffin-embedded thyroid tissue specimens were prepared for hematoxylin-eosin (HE) and Azan staining for examining follicular destruction,follicular and epithelial cell vacuolation, follicular crystallization, parenchymatous hemorrhage, follicular size, and follicular metachromasia. Follicular destruction was more frequently detected in cause of death due to asphyxia and acute head injury than in those due to other causes. There were no significant differences among the subgroups of asphyxiation. Blood thyroid hormone levels were similar as those previous reported; however, they showed no relationship with follicular destruction. Other histological changes were independent of the cause of death. These findings suggest that thyroid follicular destruction points to systemic ischemia/hypoxia rather than mechanical injury to the neck.
\end{abstract}

\section{Introduction}

We have previously measured postmortem serum levels of thyroidrelated hormones [triiodothyronine (T3), thyroxine (T4), thyroglobulin (Tg), and thyroid-stimulating hormone (TSH)] in several cases with different causes of death [1]. T3 and T4 levels are considerably higher in deaths due to mechanical asphyxiation and acute/subacute brain injury than in those due to other causes, however, those levels do not differwith respect to hanging, ligature/manual strangulation, and other types of asphyxiation [1]. TSH levelsalso do not correlate with other types of markers. These findings suggest that systemic advanced hypoxia/ischemia causes a rapid regardless of neck compression, TSHindependent release of the thyroid hormones T3 and T4 in autopsy cases. Thus, post-mortem measurements of thyroid function may aid the diagnosis of systemic ischemia/hypoxia [1,2].

Histopathological evidence is limited with respect to the relationship between thyroid hormone levels and the cause of death. The aim of the present study was to investigate the histopathological changes due to the ischemic/hypoxic response in the thyroid gland following fatality.

\section{Materials and methods}

\section{Materials}

We examined 96 serial medicolegal autopsies performed at our institute $12-72 \mathrm{~h}$ post-mortem. The cases included 64 men and 32 women, with a median age of 67 years (age range: $25-96$ years). The following causes of death were substantiated based on complete autopsy and macromorphological, micropathological, and toxicological examination: asphyxiation by neck compression ( $n=14$ : hanging, $n=$ 8 and ligature/manual strangulation, $\mathrm{n}=6$ ), other types of asphyxiation $(\mathrm{n}=7$ : choking, $\mathrm{n}=3$; chest compression, $\mathrm{n}=3$; and smothering, $\mathrm{n}=$ 1), blunt injury ( $\mathrm{n}=17$ : acute/subacute head injury, $\mathrm{n}=11$; and acute/ subacute non-head injury, $\mathrm{n}=6)$, sharp instrument injury $(\mathrm{n}=6)$, drowning (excluding bathtub drowning; $n=9$ ), and sudden cardiac death $(n=6)$. Fire fatalities $(n=37)$ were subdivided into those due to low $(<30 \% ; \mathrm{n}=10)$, intermediate $(30-60 \% ; \mathrm{n}=16)$, and high $(>60 \%$; $\mathrm{n}=11)$ carboxyhemoglobin $(\mathrm{CO}-\mathrm{Hb})$ levels. The case profiles are presented in Table 1.The case group that we used for this study is the same that we previously used to measure T3, T4, Tg, and TSH levels, as shown in Table 1 [1].

\section{Histopathology}

Serial horizontal sections of formalin-fixed, paraffin-embedded thyroid tissue specimens were prepared for hematoxylin-eosin (HE)

Correspondence to: Tomoya Ikeda, Department of Legal Medicine, Osaka City University Medical School, Asahi-machi 1-4-3, Abeno, 545-8585 Osaka, Japan, Tel: 81-6-6645-3765; Fax: 81-6-6634-3871; E-mail: ikeda.tomoya@med.osakacu.ac.jp

Key words: asphyxia, forensic pathology, hypoxia, ischemia, thyroid gland, histopathology

Received: June 17, 2017; Accepted: July 14, 2017; Published: July 17, 2017 
Table 1. Case profiles of medicolegal autopsies included in this study $(n=96)$.

\begin{tabular}{|c|c|c|c|c|c|c|c|}
\hline \multirow[t]{2}{*}{ Cause of death } & \multirow[t]{2}{*}{$\mathbf{n}$} & \multirow{2}{*}{$\begin{array}{l}\text { Male/ } \\
\text { female }\end{array}$} & \multicolumn{2}{|c|}{ Age (years) } & \multirow[t]{2}{*}{ Survival time (h) } & \multicolumn{2}{|c|}{ Post-mortem time (h) } \\
\hline & & & Range & Median & & Range & Median \\
\hline \multicolumn{8}{|l|}{ Asphyxia } \\
\hline Hanging & 8 & $5 / 3$ & $26-70$ & 51.5 & $<0.5$ & $12-60$ & 36.0 \\
\hline Strangulation & 6 & $3 / 3$ & $27-87$ & 57.0 & $<0.5$ & $24-48$ & 36.0 \\
\hline Others* & 7 & $4 / 3$ & $30-81$ & 72.0 & $<0.5$ & $12-48$ & 24.0 \\
\hline \multicolumn{8}{|l|}{ Blunt injury } \\
\hline \multicolumn{8}{|l|}{ Head injury } \\
\hline Acute & 7 & $5 / 2$ & $25-83$ & 52.0 & $<0.5$ & $12-48$ & 36.0 \\
\hline Subacute & 4 & $4 / 0$ & $47-72$ & 58.5 & $<6$ & $24-36$ & 30.0 \\
\hline \multicolumn{8}{|l|}{ Non-head injury } \\
\hline Acute & 3 & $1 / 2$ & $66-70$ & 69.0 & $<0.5$ & $24-48$ & 48.0 \\
\hline Subacute & 3 & $3 / 0$ & $44-65$ & 65.0 & $<6$ & $12-36$ & 24.0 \\
\hline Sharp instrument injury & 6 & $5 / 1$ & $45-86$ & 66.5 & $<0.5$ & $24-36$ & 36.0 \\
\hline Drowning & 9 & $4 / 5$ & $33-96$ & 73.0 & $<0.5$ & $12-48$ & 24.0 \\
\hline \multicolumn{8}{|l|}{ Fire fatalities } \\
\hline$* * \mathrm{CO}-\mathrm{Hb}<30 \%$ & 10 & $7 / 4$ & $41-86$ & 78.5 & $<0.5$ & $12-72$ & 24.0 \\
\hline $\mathrm{CO}-\mathrm{Hb}=30-60 \%$ & 16 & $11 / 5$ & $50-84$ & 71.0 & $<0.5$ & $12-48$ & 24.0 \\
\hline $\mathrm{CO}-\mathrm{Hb}>60 \%$ & 11 & $7 / 4$ & $28-91$ & 71.0 & $<0.5$ & $12-60$ & 24.0 \\
\hline Sudden cardiac death & 6 & $6 / 0$ & $40-75$ & 66.0 & $<0.5$ & $12-60$ & 36.0 \\
\hline Total & 96 & $64 / 32$ & $25-96$ & 67.0 & $<6$ & $12-72$ & 24.0 \\
\hline
\end{tabular}

* Others: choking $(\mathrm{n}=3)$, traumatic asphyxia $(\mathrm{n}=3)$, smothering $(\mathrm{n}=1)$

** CO-Hb: Carbon monoxide hemoglobin

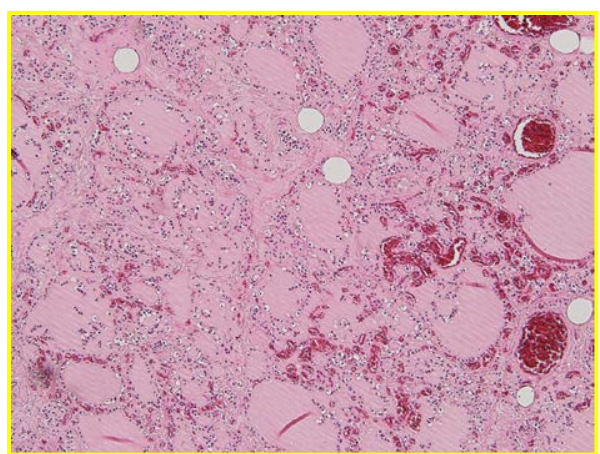

1a

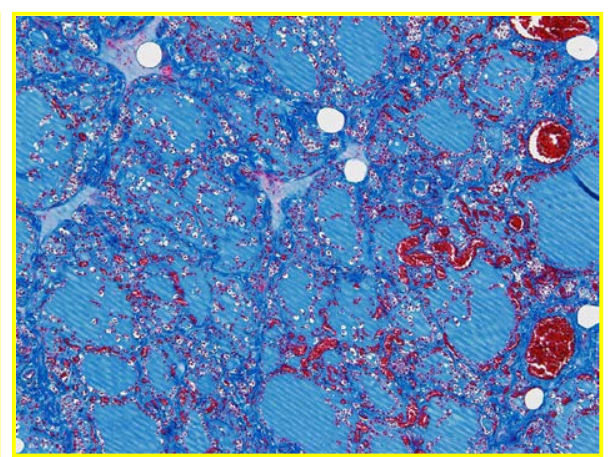

$1 b$

Figure 1. Histopathological examination of a formalin-fixed, paraffin-embedded thyroid specimen stained with (a) hematoxylin-eosin and (b) Azan staining (original magnification, 100 $\times$ ) derived from a 30 -year-old man who died by smothering. Follicular destruction in the thyroid gland suggested ischemia/hypoxia.

and Azan staining. These were then used to investigate follicular destruction (Figure 1), follicular and epithelial cell vacuolation, follicular crystallization, thyroid gland parenchymatous hemorrhage, and differences in follicular size and follicular metachromasia (Figure 2 ); these findings have been previously reported as hypoxia-related changes in the thyroid gland $[3,4]$. Two researchers independently evaluated five random fields per structure using a standard procedure and the Lumina Vision system (Mitani, CO. Japan), and estimated the mean values; inter-observer variability was usually $<10 \%$ of the measured mean values.

\section{Biochemical analyses}

Blood samples were collected from the right heart blood using syringes, and were immediately centrifuged to separate the sera. Serum T3, T4, Tg, and TSH levels were measured using electrochemiluminescence immunoassays $[1,5,6]$. The measurements of T3, T4, Tg, and TSH levels used the result that we reported so far [1].

\section{Statistical analysis}

Analyses were performed using Microsoft Excel with the Analysis ToolPak add-in, Statview (version 5.0, SAS Institute Inc.) and SPSS 17.0 (Statistical software package, Inc., Chicago, IL). The Kruskal-Wallis and Mann-Whitney U test were used for non-parametric multiple and two-group comparisons among the sex of subjects, respectively [7]. The comparisons of measured values between histopathological findings were evaluated with unpaired t-test analysis. The relationships between cause of death and histopathological findings were determined by Fisher's Exact Test. A $p$-value of $<0.05$ was considered statistically significant [8].

\section{Results}

\section{Morphological analysis of the thyroid gland}

Follicular destruction was more frequently detected in cases of death due to asphyxiation (52.4\%; 11/21 cases) and acute blunt head 
injury (71.4\%; $5 / 7$ cases) than in those due to other causes, including subacute blunt head injury (0\%; $0 / 4$ cases), acute/subacute non-head blunt injury (33.3\%; $2 / 6$ cases), sharp instrument injury $(33.3 \%, 2 / 6$ cases), fire fatality $(13.5 \%, 5 / 37$ cases; [CO-Hb level $<30 \%, 10 \%(1 / 10$ cases); CO-Hb level = 30-60\%, $18 . \%$ (3/16 cases); CO-Hb level $>60 \%$, $9.1 \%$ ( $1 / 11$ cases $)]$, drowning $(11.1 \% ; 1 / 9$ cases), and sudden cardiac death $(33.3 \% ; 2 / 6$ cases) (Table 2 and Figure 3$)$.

Regarding the asphyxiation subtypes and acute blunt head injury, no significant difference was observed between hanging-strangulation
(50\%; 7/14 cases) and other asphyxiation-related death (57.1\%; 4/7 cases) and acute blunt head injury (Figure 4).

No significant differences were observed with respect to follicular vacuolation, follicular crystallization, parenchymatous hemorrhage, follicular size, or follicular metachromasia.

\section{Correlations between thyroid-related hormone levels and histopathological findings in thyroid gland}

No correlation was found between observedmorphological changes
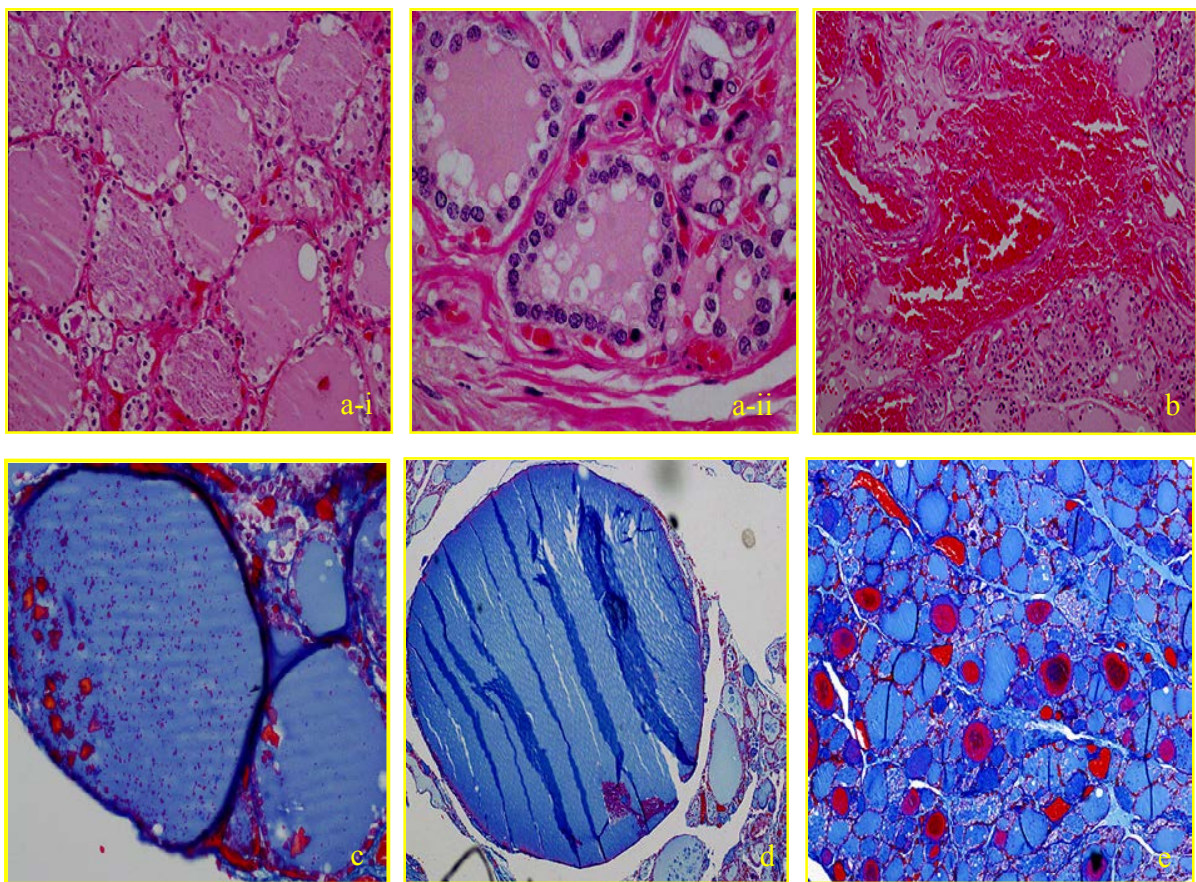

Figure 2. Histopathological examination of a formalin-fixed, paraffin-embedded thyroid gland specimen with hematoxylin-eosin and azan (a-i, vacuolation in the epithelial cells a-ii,vacuolation in the follicle;b, parenchymatous hemorrhage; c,crystallization in the follicle; d,follicular size; e, follicular metachromasia).

Table 2. Positive ratios of follicular destruction, vacuolation, parenchymatous hemorrhage, follicular size, and follicular metachromasia due to each cause of death. The thyroid follicular destruction positivity ratio was significantly higher than the ratios of other pathological changes.

\begin{tabular}{|c|c|c|c|c|c|c|}
\hline Cake of down & $\begin{array}{l}\text { Follicular } \\
\text { destruction }\end{array}$ & Vacuolation & $\begin{array}{l}\text { Crystallization } \\
\text { in the follicle }\end{array}$ & $\begin{array}{c}\text { Parenchymatous } \\
\text { hemorrhage }\end{array}$ & $\begin{array}{l}\text { Follicular } \\
\text { size }\end{array}$ & $\begin{array}{c}\text { Follicular } \\
\text { metachromasy }\end{array}$ \\
\hline Asp* & $52.4 \%(11 / 21)$ & $23.8 \%(5 / 21)$ & $28.6 \%(6 / 21)$ & $0.0 \%(0 / 21)$ & $93 \%(2 / 21)$ & $9.5 \%(2 / 21)$ \\
\hline Hanging & $62.5 \%(5 / 8)$ & $37.5(3 / 8)$ & $25.0 \%(2 / 8)$ & $0.0 \%(0 / 8)$ & $16.7 \%(1 / 8)$ & $16.7 \%(1 / 8)$ \\
\hline Strangulation & $33.3 \%(2 / 6)$ & $33.3 \%(216)$ & $0.0 \%(0 / 6)$ & $0.0 \%(0 / 6)$ & $16.7 \%(116)$ & $16.7 \%(1 / 6)$ \\
\hline Other: & $57.1 \%(4 / 7)$ & $0.0 \%(0 / 7)$ & $143 \%(1 / 7)$ & $0.0 \%(017)$ & $14.3 \%(1 / 7)$ & $0.0 \%(0 / 7)$ \\
\hline Blunt injury & $412(7 / 17)$ & $35.3 \%(6 / 17)$ & $23.5 \%(4 / 17)$ & $0.0 \%(0 / 17)$ & $17.6 \%(3 / 17)$ & $11.8 \%(2 / 17)$ \\
\hline Head injury & $45.5 \%(5 / 11)$ & $36.4 \%(4111)$ & $27.3 \%(3 / 10$ & $0.0 \%(0 / 11)$ & $9.1 \%(1 / 11)$ & $9.1 \%(1 / 11)$ \\
\hline Acute & $71.4 \%(5 / 7)$ & $42.9 \%(3 / 7)$ & $42.9 \%(3 / 7)$ & $0.0 \%(0 / 7)$ & $0.0 \%(0 / 7)$ & $0.0 \%(0 / 7)$ \\
\hline Subacute & $0.0 \%(0 / 4)$ & $25.0 \%(1 / 4)$ & $0.0 \%(0 / 4)$ & $0.0 \%(0 / 4)$ & $25.0 \%(1 / 4)$ & $25.0 \%(1 / 4)$ \\
\hline Non-head Injury & $33.3(2 / 6)$ & $33.3 \%(2 / 6)$ & $16.7 \%(1 / 6)$ & $0.0 \%(0 / 6)$ & $33.3 \%(2 / 6)$ & $16.7 \%(1 / 6)$ \\
\hline Acute & $33.3 \%(1 / 3)$ & $33.3 \%(1 / 3)$ & $33.3 \%(1 / 3)$ & $0.0 \%(0 / 3)$ & $66.6 \%(2 / 3)$ & $33.3 \%(1 / 3)$ \\
\hline Subacute & $33.3 \%(1 / 3)$ & $33.3 \%(1 / 3)$ & $0.0 \%(0 / 3)$ & $0.0 \%(0 / 3)$ & $0.0 \%(0 / 3)$ & $0.0 \%(0 / 3)$ \\
\hline Sharp Instrument 'Nut" & $33.3 \%(2 / 6)$ & $33.3 \%(216)$ & $0.0 \%(0 / 6)$ & $16.7 \%(1 / 6)$ & $16.7 \%(1 / 6)$ & $0.0 \%(0 / 6)$ \\
\hline Drowning & $11.1 \%(1 / 9)$ & $22.2 \%(29)$ & $33.3 \%(3 / 9)$ & $0.0 \%(0 / 9)$ & $11.1 \%(1 / 9)$ & $22.2 \%(2 / 9)$ \\
\hline Fire fatalities & $13.3 \%(5 / 37)$ & $43.2 \%(16 / 37)$ & $21.6 \%(8 / 37)$ & $0.0 \%(0 / 37)$ & $10.8 \%(4 / 37)$ & $5.4 \%(2 / 37)$ \\
\hline $\mathrm{CO}-\mathrm{Hb}<30 \%$ & $10.0(1 / 10)$ & $40.0 \%(4 / 10)$ & $30.0 \%(3 / 10)$ & $0.0 \%(0 / 10)$ & $10.0 \%(1 / 10)$ & $0.0 \%(0 / 10)$ \\
\hline $\mathrm{CO}-\mathrm{Hb}=30-60 \%$ & $18.8 \%(3 / 16)$ & $50.0 \%(8 / 16)$ & $250 \%(4 / 16)$ & $0.0 \%(0 / 16)$ & $6.3 \%(1 / 16)$ & $123 \%(2 / 16)$ \\
\hline $\mathrm{CO}-\mathrm{Hb}>60 \%$ & $9.1 \%(1 / 1)$ & $36.4 \%(4 / 11)$ & $9.1 \%(1 / 11)$ & $0.0 \%(0 / 11)$ & $182 \%(2 / 11)$ & $0.0 \%(0 / 11)$ \\
\hline Sudden cardiac death & $33.3 \%(2 / 6)$ & $50.0 \%(3 / 6)$ & $66.7 \%(4 / 6)$ & $0.0 \%(0 / 6)$ & $0.0 \%(0 / 6)$ & $0.0 \%(0 / 6)$ \\
\hline Total & $29.2 \%(28 / 96)$ & $35.4 \%(34 / 96)$ & $26.0 \%(25 / 96)$ & $1.0 \%(1 / 96)$ & $11.5 \%(11 / 96)$ & $83 \%(8 / 96)$ \\
\hline
\end{tabular}




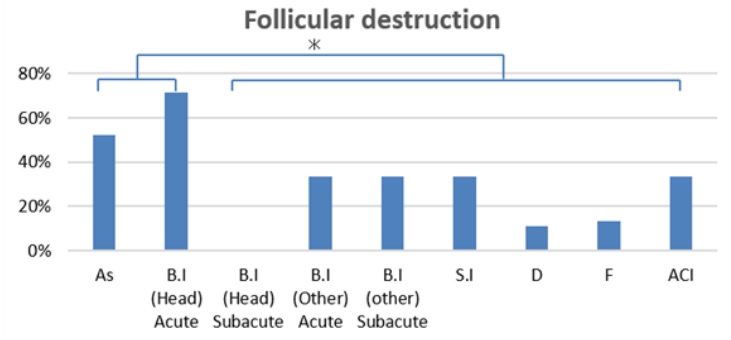

Crestallization in the follicle

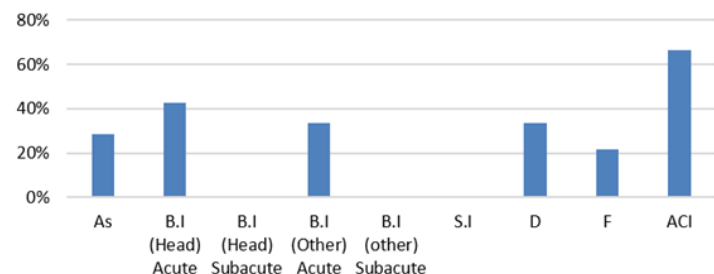

Follicular size

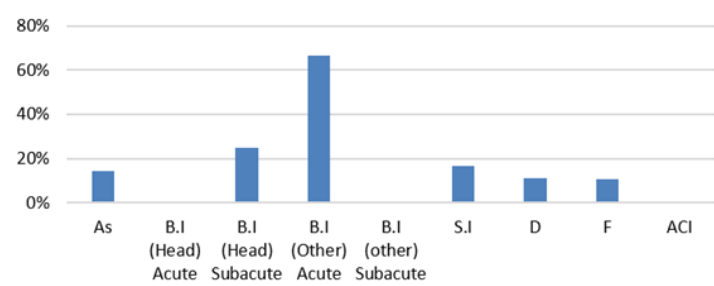

Vacuolation

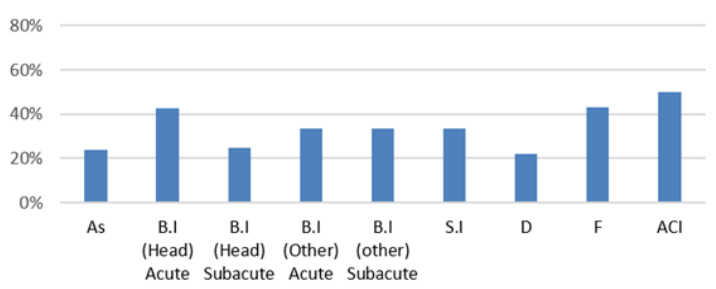

Parenchymatous hemorrhage

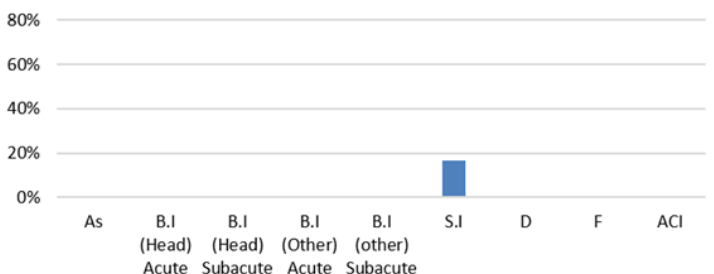

Follicular metachromasy

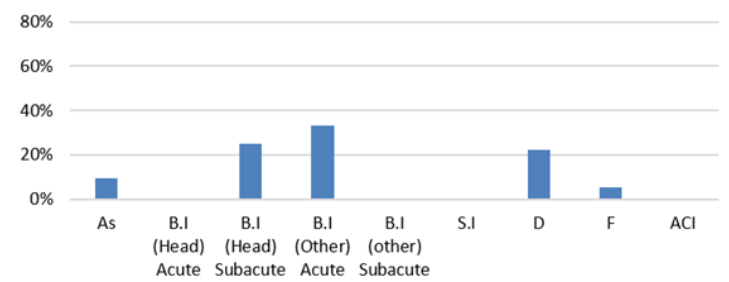

Figure 3. Graph shows the ratio of pathological change in each cause of death group. Follicular destruction was more frequently detected in cases involving asphyxia and acute/subacute blunt head injury (As, asphyxiation; B I, blunt injury; SI, sharp instrument injury; F, fire fatality; D, drowning; SCD, sudden cardiac death; *p $<0.05$ ).

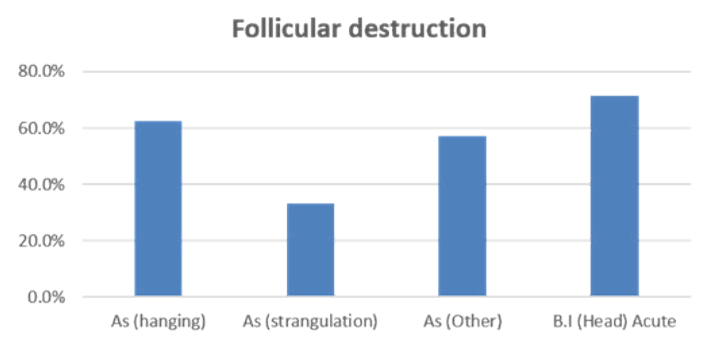

Crestallization in the follicle

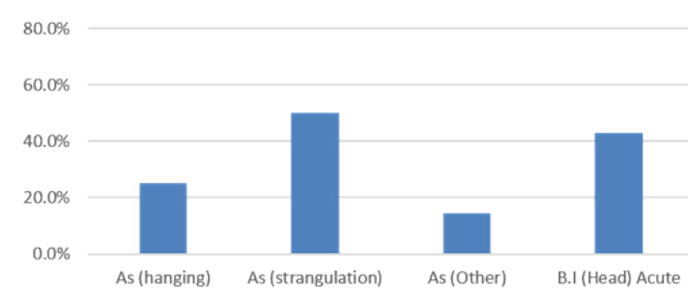

Follicular size

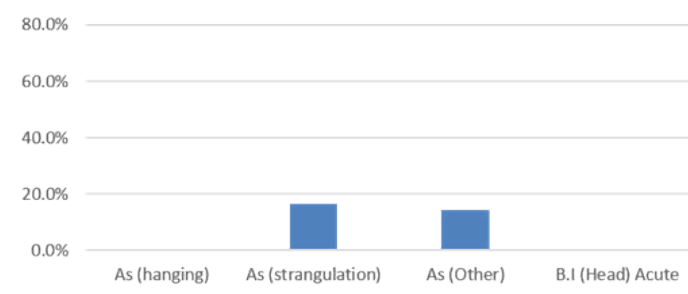

Vacuolation

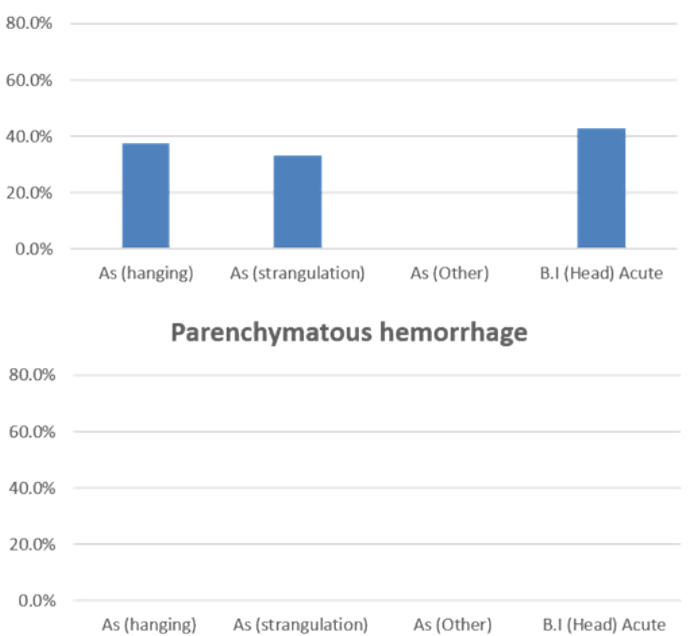

Follicular metachromasy

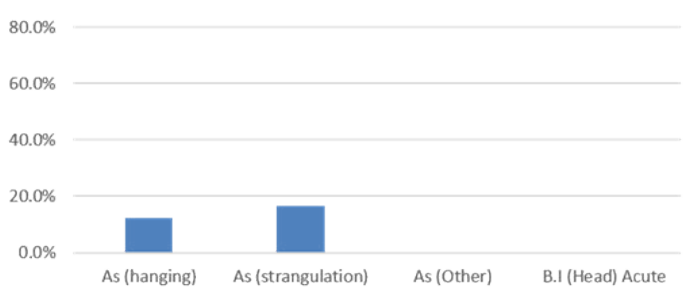

Figure 4.Graph showing the extent of pathological changes due to each type of asphyxiation and acute blunt head injury. No significant differences were detectable in the samples observed (As, asphyxiation; B I, blunt injury). 
and serum thyroid-related hormone levels [1].

\section{Discussion}

No differences were observed with respect to the cause of death in terms offollicularvacuolation, follicularcrystallization, parenchymatous hemorrhage, follicular size, or follicular metachromasia. However, follicular destruction was more frequently detected in cases of death due to asphyxiation and acute/subacute blunt head injury than in those due to other causes. Asphyxiation and acute blunt head injury are suggested to cause the acute ischemic/hypoxic condition, and this systemic condition may trigger follicular destruction.

We also did not observe a significant relationship between thyroid pathology and levels of thyroid-related hormones levels, but emphasize that it is critical to evaluate thyroid pathological changes for information that would support a diagnosis of systemic ischemia/hypoxia.In addition, our results showed that parenchymatous hemorrhage was almost absent with respect to all types of deaths. It can be said that the reason for the rise of hormones is not physically broken.

Our results suggest that postmortem histological data will facilitate a diagnosis of systemic ischemia/hypoxia, but they cannot be used on their own to confirm or rule out physical neck pressure. Accordingly, pathophysiological index have been suggested as an ischemia/hypoxia related to asphyxia.

\section{Disclosure of potential conflicts of interest}

The authors declare that there were no conflicts of interest regarding the publication of this paper.

\section{References}

1. Tani N, Michiue T, Oritani S, Potente S, Morioka F, Ishikawa T (2017) Post-mortem serum thyroid hormone levels as a potential marker of hypoxia/ischemia in medicolegal autopsy cases. Leg Med (in submitted).

2. Dressler J, Mueller E (2006) High thyroglobulin (Tg) concentrations in fatal traumatic brain injuries. Am J Forensic Med Pathol 27: 280-282.

3. Okabe Y (1969) Pathological study of hypoxidotic change, especially of the thyroid Showa Univ J Med Sci. 29:465-474. DOI: 10.14930/jsma1939.29.465 (Jaoanese)

4. Okłota M, Niemcunowicz-Janica A, Dziecioł J, Ptaszyńska-Sarosiek I, Klim B, Sackiewicz A, Załuski J, Szeremeta M (2011) Morphological, microscopic changes in the thyroid gland in the cases of hanging in vertical position with open and closed noose. Arch Med Sadowej Kryminol 61:331-336. (Polish)

5. Kazerouni F, Amirrasouli H (2012) Performance characteristics of three automated immunoassays for thyroid hormones. Caspian J Intern Med 3: 400-404.

6. Sánchez-Carbayo M, Mauri M, Alfayate R, Miralles C, Soria F (1999) Analytical and clinical evaluation of TSH and thyroid hormones by electrochemiluminescent immunoassays. Clin Biochem 32: 395-403.

7. Ishikawa T, Inamori-Kawamoto O, Quan L, Michiue T, Chen JH, Wang Q, Zhu BL, Maeda H (2014) Postmortem urinary catecholamine levels with regard to the cause of death. Leg Med 16: 344-349. doi: 10.1016/j.legalmed.2014.07.006.

8. Ruokonen E, Ilkka L, Niskanen M, Takala J (2002) Procalcitonin and neopterin as indicators of infection in critically ill patients. Acta Anaesthesiol Scand 46: 398-404.

Copyright: (C2017 Ikeda T. This is an open-access article distributed under the terms of the Creative Commons Attribution License, which permits unrestricted use, distribution, and reproduction in any medium, provided the original author and source are credited. 